\title{
Biokonserwatyzm i preferencja status quo ${ }^{1}$
}

Wojciech Lewandowski (Katolicki Uniwersytet Lubelski Jana Pawła II, Lublin)

Na tle wszystkich debat bioetycznych podział na zwolenników i przeciwników ulepszania ludzkiej kondycji nie budzi większego zdziwienia i może być interpretowany jako przełożenie na nowy grunt trwających od lat sporów między zwolennikami i przeciwnikami jak najszerszego wykorzystywania zdobyczy nauk biomedycznych. Dla pierwszych projekt zwiększania ludzkich możliwości w aspekcie fizycznym, kognitywnym lub moralnym stanowi kolejną odsłonę zastosowania wciąż rozwijającej się wiedzy i technologii w celu podnoszenia jakości ludzkiego życia. Dla drugich każda ingerencja powinna być poprzedzona ostrożną refleksją pozwalającą na zidentyfikowanie możliwych zagrożeń oraz moralnych ograniczeń tego rodzaju praktyk. W odróżnieniu od większości innych dyskusji bioetycznych debata dotycząca ulepszania ludzkiej kondycji odnosi się do ingerencji, z których większość nadal nie jest dostępna. Obie strony dyskusji używają argumentów opartych na przewidywanym dalszym rozwoju nauk i technologii biomedycznych oraz na przewidywanych skutkach tego rozwoju. Dyskusja na temat przyszłych skutków nowych działań, co do których nie ma jeszcze empirycznych dowodów skuteczności zawsze obarczona jest ryzykiem myślenia utopijnego lub apriorycznego odrzucania wszelkich zmian. Pomiędzy tymi skrajnymi stanowiskami znajduja się te, które oferuja argumentację opartą na porównaniu ulepszania ludzkiej kondycji $\mathrm{z}$ terapią oraz tradycyjnymi sposobami doskonalenia możliwości człowieka. Ta pośrednia droga nie eliminuje jednak całkowicie polaryzacji. Zwolennicy ulepszania ludzkiej natury często przyjmują założenie, że nie istnieje moralnie istotna różnica między terapią a ulepszającymi ingerencjami. Przeciwnicy natomiast utrzymują tezę, iż ingerencje te stanowią przekroczenie progu bezpieczeństwa, za którym dotychczasowe źródła obiektywnych wartości, takie jak ludzka natura, autonomia lub godność zostaną wystawione na duże ryzyko (Kass 1997; Fukuyama 2002; Habermas 2003; McKibben 2003; President's Council on Bioethics 2003; Sandel 2007).

Najczęściej stanowiskom biokonserwatywnym zarzuca się używanie retoryki zamiast argumentacji, ignorowanie biologicznych faktów przy odwoływaniu się do pojęcia natury oraz formułowanie tez dotyczących aktualnej lub przyszłej ludzkiej psychiki bez poparcia ich empirycznymi

1 Projekt został sfinansowany ze środków Narodowego Centrum Nauki przyznanych na podstawie decyzji numer DEC-2013/10/E/HS5/00157. 
dowodami (Buchanan 2011b, 2-10). Jeden z najbardziej interesujących zarzutów przeciwko biokonserwatyzmowi polega na próbie wykazania, iż sprzeciw wobec projektu ulepszania ludzkich możliwości opiera się na błędzie związanym $\mathrm{z}$ nieuzasadnioną preferencją aktualnego stanu rzeczy. W niniejszym artykule przedstawię możliwości obrony stanowiska biokonserwatywnego przed tym zarzutem. W części pierwszej omówię sformułowany przez Nicka Bostroma i Toby’ego Orda zarzut odwołujący się do efektu status quo, następnie omówię, w jaki sposób zarzut ten wpływa na ryzyko niekonkluzywności uzasadnienia biokonserwatyzmu. $\mathrm{Na}$ koniec natomiast przedstawię próbę obrony biokonserwatyzmu opartą na kategorii "ludzkiego uprzedzenia" Bernarda Williamsa.

\section{Efekt status quo}

Istotą zarzutu popełnienia błędu status quo jest wskazanie na fakt, iż preferencja obecnego stanu rzeczy może wpłynąć na niewłaściwe oszacowanie możliwych korzyści i strat. Według Bostroma i Orda w kontekście ulepszania ludzkiej kondycji ów błąd może być popełniony przy odpowiedzi na pytanie, czy mamy powody, by wierzyć, że bilans długoterminowych konsekwencji udoskonalania ludzkich zdolności będzie korzystny. Autorzy zawężają to pytanie do kwestii ulepszania zdolności kognitywnych, takich jak płynność mowy, pamięć, abstrakcyjne rozumowania, inteligencja społeczna, orientacja $\mathrm{w}$ terenie, zdolność liczenia czy talent muzyczny. Zdaniem autorów fundamentalną trudnością w pytaniu o moralną ocenę ulepszających ingerencji jest radykalna niepewność zarówno co do tego, do jakich skutków one doprowadzą, jak i co do wartości tych skutków. Autorzy twierdzą, że $\mathrm{z}$ tego rodzaju radykalną niepewnością mamy do czynienia w wielu sytuacjach życiowych - przy decyzji o zawarciu małżeństwa lub o wsparciu znacznych reform społecznych. Nieprzewidywalność indywidualnego ludzkiego życia oraz systemów społecznych sprawiają, że tego rodzaju decyzje nie są więc oparte na twardych dowodach naukowych, lecz na subiektywnym, intuicyjnym osądzie. Jakość tego osądu zależy od tego, czy jest on oparty na znajomości faktów potrzebnych do podjęcia decyzji, czy na uprzedeniach.

Najbardziej znany opis efektu status quo został sformułowany przez Tversky'ego i Kahnemana. Na podstawie serii eksperymentów psychologicznych wykazali oni, że preferencja dla utrzymania status quo jest konsekwencją awersji wobec strat. W większości przypadków wybory dokonywane między wygranymi różniącymi się wielkością i prawdopodobieństwem wystąpienia, nie opierały się na faktycznym przeliczeniu tych wartości, lecz na szacowanej wielkości emocjonalnego poczucia straty w przypadku przegranej (Kahneman \& Tversky 1979). Tezy Tversky'ego i Kahnemana są poparte zarówno obserwacjami biologicznymi 
(zwiększony wysiłek w celu uniknięcia strat niż w celu osiągnięcia korzyści jest wspólny ludziom i pozostałym zwierzętom), socjologicznymi (opór wobec reform), jak i ekonomicznymi (Kahneman 2011, 304-306).

Zdaniem Bostroma i Orda efekt status quo w dyskusjach bioetycznych można zidentyfikować na podstawie następującego testu.

Test odwrócenia: Gdy uznaje się, iż propozycja zmiany pewnego parametru przyniesie złe konsekwencje, należy rozważyć zmianę tego samego parametru w odwrotnym kierunku. Jeśli ta zmiana również zostanie uznana za prowadzącą do złych konsekwencji, wówczas na tym, kto doszedł do obu tych wniosków, spoczywa ciężar uzasadnienia, dlaczego nasza kondycja nie może zostać ulepszona przez zmianę tego parametru. Jeśli nie potrafi on tego wyjaśnić, wówczas mamy powód, by przypuszczać, że popełnił on błąd status quo (Bostrom \& Ord 2006, 664-665).

Zgodnie z powyższym testem autorzy opozycyjni wobec zwiększania średniego ilorazu inteligencji w ludzkiej populacji powinni wykazać, czy zmniejszenie tej wartości w populacji również byłoby niekorzystne. Wydaje się, że większość argumentów biokonserwatywnych dość łatwo zdałaby ten test. Jeśli według Jürgena Habermasa kształtowanie genetycznego uposażenia dzieci sprawia, iż nie są one traktowane jako strona procesu komunikacyjnego lub jako autonomiczni autorzy swojej drogi życiowej, to nie ma znaczenia, czy ingerencje genetyczne powodują wzrost, czy pomniejszenie możliwości kognitywnych. Na tej podstawie można sądzić, że co najmniej w niektórych odmianach biokonserwatyzmu negatywna ocena ulepszających ingerencji nie jest oparta na błędnej kalkulacji skutków spowodowanej awersją wobec strat, lecz na deontologicznych ograniczeniach stanowiących racje konkurencyjne wobec konsekwencjalnych.

Możliwe są co najmniej trzy odpowiedzi na tego typu obronę. Po pierwsze, można uznać, że deontologiczny charakter argumentów przeciwko poprawianiu inteligencji jest pozorny, zaś faktycznie opiera się na wskazywaniu niekorzystnych konsekwencji tego typu zmian. Założenie normatywności natury ludzkiej można uznać za równoznaczne ze stwierdzeniem, iż obecna kondycja znajduje się w stanie równowagi umożliwiającej realizowanie wszystkich wartości, na jakie zwracają uwagę biokonserwatyści. Jeśli ich zdaniem zaburzenie tej równowagi w którąkolwiek ze stron byłoby niesłuszne, to brak wystarczającego uzasadnienia, iż niemożliwe byłoby realizowanie tych wartości po zmianie, pozwalałby na przypuszczenie, że stanowisko to jest oparte na błędzie status quo (Żuradzki 2014, 219). Po drugie, możliwe jest osłabienie deontologicznych ograniczeń poprzez wskazanie, iż jeśli biomedyczne ingerencje byłyby jedynym sposobem eliminacji możliwych naturalnych zagrożeń związanych z pogarszaniem ludzkiej kondycji, to te same racje pozwalają na uzasadnienie tych ingerencji w celach pozaterapeutycznych (Bostrom \& Ord 2006, 673). Po trzecie, 
możliwe jest dopuszczenie uwzględnienia deontologicznych ograniczeń, ale jedynie w takim zakresie, że wartość pewnego stanu rzeczy może zostać pomniejszona, jeśli ów stan rzeczy został spowodowany przez złamanie tych ograniczeń (Bostrom \& Ord 2006, 656-657). Pozostawanie przy absolutnej obowiązywalności deontologicznych ograniczeń również mogłoby być konsekwencją błędu status quo.

Należy zauważyć, że kryterium, na którym oparty jest test odwrócenia, nie jest precyzyjne. Możliwość uzasadnienia dojścia do obu wniosków może być rozumiana bardzo szeroko jako podanie jakichkolwiek racji uzasadniających zmiany lub bardzo wąskojako podanie przekonujących racji. Pierwsza opcja sprawia, że większości stanowisk biokonserwatywnych nie można byłoby zarzucić błędu status quo. Opcja druga wiąże się z tym, że w kontekście sporu o modyfikację jakiegokolwiek parametru brak uzasadnienia satysfakcjonującego jedną ze stron tego sporu pozwalałby jej na sformułowanie podejrzenia o popełnieniu błędu status quo, sprowadzając argument opierający się na tym teście do argumentu ad personam, zaś całą dyskusję dotyczącą ulepszania ludzkiej kondycji-do psychologii dyskursu naukowego. Krytycy biokonserwatyzmu unikają tej pułapki, uznając, że istnieją pewne racje przeciwko ulepszaniu ludzkiej kondycji, lecz jednocześnie stwierdzając, iż racje te nie są wystarczające do uzasadnienia zaprzestania badań nad doskonaleniem człowieka.

\section{Problem konkluzywnych racji}

Istnienie różnych rodzajów racji dopuszczają sami zwolennicy ulepszania ludzkich możliwości. Julian Savulescu w uzasadnieniu swojej słynnej zasady prokreacyjnego dobroczynienia stwierdza, iż powinność przeprowadzania tych ingerencji jest powinnością typu prima facie. Powinność tego typu oznacza posiadanie dobrych racji do wybrania doskonalących zmian, jednak racje te są rozstrzygające tylko wówczas, jeśli nie istnieją inne racje sprzeciwiające się tym zmianom. Idąc tym tropem można uznać, że zarzuty biokonserwatystów odwołujące się do prawa do „otwartej przyszłości” czy „otwarcia na nieproszone” nie opierają się na założeniu, iż świat, w którym średni iloraz inteligencji wynosiłby 180 , byłby światem gorszym niż obecny, lecz na założeniu, że istnieją racje za tym, by nie wybierać ingerencji zaprojektowanych w celu stworzenia takiego świata.

Według Allena Buchanana autorzy tacy jak Fukuyama, Kass czy Sandel, sprzeciwiający się szerokiemu dostępowi do przyszłych technologii ulepszających ludzką kondycję, opierają swoją argumenatację nie na rozważaniu racji za i przeciw ulepszaniu ludzkiej kondycji, lecz na formułowaniu racji przeciwko tego typu ingerencjom. Na tej podstawie Buchanan dochodzi do wniosku, że wszyscy oni przyjmują tzw. stanowisko konkluzywnych racji (Buchanan 2008). 
Stanowisko konkluzywnych racji: Każda konkluzywna racja przeważa wszystkie przeciwstawne racje.

Zdaniem Buchanana biokonserwatywne racje przeciwko ulepszaniu ludzkiej kondycji trudno uznać za konkluzywne. Jeśli ulepszanie ludzkiej kondycji zagraża ludzkiej naturze, może prowadzić do alienacji i utraty naszego prawdziwego „ja” lub wyraża niewdzięczność i brak otwartości na „nieznane”, to dokładnie te same racje musiałyby być konkluzywne również w przypadku wszystkich ingerencji, również tych, które nie wiążą się $\mathrm{z}$ biomedycznym ulepszeniem ludzkiej kondycji (Buchanan 2011a, 150-151). Według Buchanana jedynym sposobem uniknięcia tego absurdalnego wniosku jest uznanie, że racje te nie są konkluzywne i nie mogą być brane pod uwagę inaczej niż poprzez wyważenie ich z racjami za ulepszającymi ingerencjami.

Odrzucenie modelu ważenia racji za i przeciw doskonalącym ingerencjom może nasuwać kolejne podejrzenia, że biokonserwatyści popełniają błąd status quo. Wydaje się jednak, że stanowisko konkluzywnych racji jest przyjmowane w etyce na tyle często w kontekście innych problemów moralnych, że również tym razem takie podejrzenie może zsotać uchylone. Najczęściej uznaje się, że racjami konkluzywnymi są te, które odwołują się do prognozy możliwych krzywd, do jakich mogłoby prowadzić dane działanie. Interesującą próbę zastosowania tej kategorii do kwestii ulepszania ludzkiej kondycji podjął Tom Douglas. Według Douglasa można wskazać co najmniej pięć możliwych krzywd, do jakich mogą doprowadzić ulepszające ingerencje. Po pierwsze, krzywdzące użycie ulepszających technologii, na przykład do działań militarnych. Po drugie, krzywda związana z osiągnięciem przewagi konkurencyjnej osób ulepszonych względem nieulepszonych. Po trzecie, perspektywa przymusowego ulepszania, związana z tym, że zwiększanie się liczby osób ulepszonych może wywierać presję na nieulepszonych lub doprowadzić do uchwalenia prawa uznającego ulepszanie za obowiązek. Po czwarte, zwiększenie podatności na krzywdzenie innych, polegające na tym, że ludzie posiadający zwiększone możliwości mogą posiadać mniejszą wrażliwość i empatię wobec nieulepszonych, o ile ulepszaniu kognitywnemu nie będzie towarzyszyło ulepszanie na poziomie emocjonalnym². Po piąte wzrost akceptowalności dopuszczalnej krzywdy, czyli możliwe ryzyko wskazywania na okoliczności, które usprawiedliwiałyby krzywdzenie osób, które nie zostały poddane ulepszającym ingerencjom lub wykluczenie osób nieulepszonych z publicznego dyskursu i zrównanie ich praw obywatelskich z prawami dzieci lub osób upośledzonych. Według Douglasa powyższe racje mogłyby zostać uznane za konkluzywne, gdyby wszystkie ulepszające ingerencje skutkowały niedającą się usprawiedliwić krzywdą innych ludzi lub

2 Według Johna Harrisa samo doskonalenie kognitywne pozwoli na uniknięcie tych konsekwencji bez konieczności ingerencji na poziomie motywacyjnym (Harris 2010). 
gdyby większość tych ingerencji posiadała takie skutki przy jednoczesnym braku jakiejkolwiek formy regulacji państwowej pozwalającej na wyeliminowanie krzywdzących interwencji i dopuszczenie bezpiecznych (Douglas 2015, 25-27).

Inną strategią wykazania konkluzywności racji przeciwko ulepszaniu ludzkiej kondycji jest odwołanie się do stosowanej w etyce środowiskowej zasady ostrożności. Według Neila Mansona każda wersja tej zasady posiada trzyczęściową strukturę: warunek szkody, odwołujący się do skutku, w stosunku do którego należy zastosować skalę ostrożności, warunek wiedzy, dotyczący możliwości stwierdzenia związku przyczynowo-skutkowego między danym działaniem a rozważaną szkodą, oraz środki zaradcze, jakie należy podjąć w związku z tym działaniem, by nie dopuścić do szkód (Manson 2002, 263-265). W kontekście dyskusji dotyczącej ulepszania ludzkiej kondycji zadaniem biokonserwatystów byłoby uzasadnienie, iż dwa pierwsze warunki są spełnione, zaś właściwym środkiem zaradczym jest powstrzymanie się od tego typu ingerencji. Zasada ostrożności wspierałaby ponadto pogląd, iż ciężar uzasadnienia ulepszania ludzkiej kondycji wraz z działaniami osłonowymi, pozwalającymi na uniknięcie ewentualnych krzywd spoczywa na tym, kto uważa, że należy dążyć do realizacji ryzykownej polityki lub projektu. Odparcie zarzutu błędu status quo polegałoby na przyjęciu słabej lub silnej odmiany zasady ostrożności. Obie wiążą się jednak z pewnymi problemami.

Silna zasada ostrożności: Gdy jakiś projekt jest związany $\mathrm{z}$ ryzykiem poważnej szkody, to nawet przy braku naukowych dowodów tego ryzyka nie powinien być realizowany, niezależnie od oczekiwanych korzyści (Sunstein 2005, 19-20).

Główny zarzut przeciwko tej wersji zasady opiera się na porównaniu podjęcia ryzykownego działania $\mathrm{z}$ możliwymi korzyściami. Jeśli jakieś działanie jest ryzykowne, ale utrzymanie status quo jest jeszcze bardziej ryzykowne, wówczas silna zasada ostrożności implikuje niewłaściwy wybór. Jeśli natomiast silna zasada ostrożności ma być stosowana do wszystkich możliwości wyboru, to w sytuacji, w której każda z nich niesie ze sobą jakieś poważne ryzyko, należy uznać, że nie należy wybierać żadnej z nich (Sunstein 2005, 42-48).

Słaba zasada ostrożności: Wybierając między alternatywnymi strategiami, powinniśmy przypisać większą wagę ryzyku związanemu z daną strategią niż możliwym korzyściom (Sunstein 2005, 18-19).

Uogólnienie tej zasady na wszystkie sytuacje wyboru implikowałoby jednakowe ostrożne traktowanie ryzyka związanego $z$ katastrofalnymi i nieodwracalnymi skutkami oraz ryzyka związanego $\mathrm{z}$ akceptowalnymi i odwracalnymi szkodami. Jednym ze sposobów obrony stanowiska 
biokonserwatywnego byłoby uznanie, iż obecna ludzka kondycja stanowi wartość, której utrata byłaby katastrofą. Najbardziej znaną próbą zastosowania tej strategii jest heurystyka strachu Hansa Jonasa, oparta przede wszystkim na jakościowo wyższej wartości dotychczasowego dziedzictwa ewolucji w postaci możliwości poznania prawdy, wartościowania i wolności (Jonas 1996, 75). Ewentualna utrata tych możliwości stanowi zdaniem Jonasa wystarczającą rację do tego, by nie włączać ich w jakąkolwiek kalkulację dopuszczającą ryzyko ich utraty. Podstawowym założeniem zasady ostrożności wydaje się zatem szczególnie wartościowy status aktualnej ludzkiej kondycji. Charakterystyczne dla tego rodzaju argumentacji jest przypisanie chronionym wartościom nieskończonej wielkości, dzięki czemu możliwe jest uzasadnienie, iż zwiększenie ludzkich możliwości za pomocą ingerencji biomedycznych nie zwiększa obiektywnej wartości gatunku ani poszczególnych jednostek. Uzasadnienie to pozwala stwierdzić, że ryzyko jest jedynym czynnikiem, który należy brać pod uwagę. Argument ten można jednak odwrócić: jeśli ingerencje biomedyczne nie mogą zmniejszyć ani zwiększyć wewnętrznej wartości ludzkiego gatunku, wówczas wystarczającym kryterium dopuszczalności tych ingerencji jest bilansowanie pozostałych korzyści i strat. Ponadto, zarzut błędu status quo można odnieść do przypisania aktualnej ludzkiej kondycji leksykalnej wyższości nad wszelkimi innymi wartościami (inne aspekty tej argumentacji przedstawia Hainz 2012).

Wydaje się, że uzasadnienie obiektywnej wartości gatunku ludzkiego nie jest konieczne do uniknięcia zarzutu niekonkluzywności opartej na błędzie status quo. Odwołanie się do różnych rodzajów racji praktycznych daje możliwość stwierdzenia, że nawet jeśli porównanie korzyści i strat przemawia za doskonalącymi ingerencjami, to obiekcje wobec tych ingerencji nie świadczą o irracjonalnym uprzedzeniu.

\section{3. "Ludzkie uprzedzenie" wobec doskonalących ingerencji}

Czy możliwa jest sytuacja, w której podmiot lub grupa podmiotów, nie popełniając błędu status quo, posiadają konkluzywne racje, by nie wybrać pewnej zmiany, nawet jeśli po tej zmianie uznaliby ją za uzasadnioną i pożądaną? Aby móc stwierdzić, czy konserwatyzm związany z ulepszaniem ludzkiej kondycji jest wynikiem uprzedzenia, można porównać dwa sposoby sformułowania pytania o uzasadnienie poszczególnych ingerencji:

1. „Czy należy stosować ingerencje zwiększające ludzkie możliwości?”;

2. „Czy podmiot ma dobre racje do tego, by zdecydować się na ingerencje, które poprawią jego możliwości?".

Pytanie pierwsze można zinterpretować na co najmniej dwa sposoby:

1.a. “Czy z bezstronnego punktu widzenia należy stosować ingerencje zwiększające ludzkie możliwości?”; 
1.b. “Czy z naszego punktu widzenia jako przedstawicieli gatunku homo sapiens, należy stosować ingerencje zwiększające inteligencję?”.

Interpretacja pierwsza, którą przyjmują zwolennicy ulepszających ingerencji, zakłada możliwość oceny zmian z bezstronnego punktu widzenia lub innymi słowy "z punktu widzenia uniwersum", w którym nie bierze się pod uwagę indywidualnych cech i preferencji podmiotu dokonującego oceny ${ }^{3}$. Druga interpretacja zakłada zadanie tego pytania $\mathrm{z}$ punktu widzenia przedstawicieli gatunku, w którym wprowadzone zostaną te zmiany. Podstawą zarzutu opartego na teście odwrócenia wydaje się uznanie, że punkt widzenia przedstawicieli gatunku homo sapiens może być stronniczy i oparty na uprzedzeniach. $\mathrm{W}$ odniesieniu do kwestii radykalnego ulepszania, czyli wprowadzania do gatunku ludzkiego cech, których żaden z przedstawicieli tego gatunku dotychczas nie posiadał, zarzut ten miałby dokładnie tę samą strukturę jak zarzut szowinizmu gatunkowego (Zarzut ten $\mathrm{w}$ kontekście innych ingerencji biomedycznych analizuje (DeGrazia 2007). Zgodnie z tym zarzutem faworyzowanie interesów przedstawicieli własnego gatunku w stosunku do interesów przedstawicieli innych gatunków jest wynikiem uprzedzenia (Singer 1995, 6-9).

Argumentacja sformułowana przez Bernarda Williamsa w tekście "The Human Prejudice" (Williams 2006) pozwala na odrzucenie zarówno zarzutu szowinizmu gatunkowego, jak i zarzutu uprzedzenia wobec ingerencji ulepszających ludzką kondycję. Według Williamsa podmioty, które zadają pytanie o preferowanie osobników własnego gatunku robią to już $\mathrm{w}$ kontekście wyznawanych przez siebie wartości. Z tego punktu widzenia preferowanie przedstawicieli własnego gatunku nie byłoby wyrazem uznania absolutnej wyższości ludzi nad zwierzętami, lecz jedynie konsekwencją faktu, iż współprzedstawiciele tego gatunku są dla nas ważniejsi niż osobniki innych gatunków.

Zdaniem krytyków tego stanowiska, aby móc je utrzymać, należy wskazać racje za preferowaniem ludzi nad zwierzętami. Bez wskazania racji, preferencja ta nadal będzie nieusprawiedliwionym uprzedzeniem, takim jak seksizm czy rasizm, dla których jedynym kryterium postępowania wobec innych jest to, czy są oni "tacy jak my” (Singer 2009, 572-573). Według Williamsa istnieje jednak różnica między próbami uzasadnienia rasizmu i seksizmu a próbami uzasadnienia preferencji opartej na przynależności gatunkowej. W pierwszym przypadku mamy do czynienia $\mathrm{z}$ próba uzasadnienia ad hoc dyskryminujących praktyk, poprzez odwołanie się do niewłaściwych racji, na przykład opartych na fałszywych założeniach dotyczących gorszych możliwości intelektualnych dyskryminowanej grupy. W

3 Niektóre koncepcje ulepszania moralnego zakładają modyfikacje zwiększające dyspozycje ludzi do rozstrzygania problemów moralnych z tego właśnie punktu widzenia (Savulescu \& Persson 2012). 
drugim przypadku stwierdzenie "to jest ludzka istota” nie wymaga jakiegoś dodatkowego uzasadnienia związanego $\mathrm{z}$ cechami różniącymi ludzi od zwierząt. Umiejętność posługiwania się złożonymi i zawierającymi abstrakcyjne pojęcia językami, tworzenie i przekazywanie dzieł kultury i rozwój technologiczny wydają się nie mieć związku z naszą preferencją wobec innych ludzi. Zdaniem Williamsa mamy powód, by poszerzać naszą sympatie na inne grupy ludzi lub zwierząt, ale tylko wtedy, kiedy widzimy je jako aspekty ludzkiego życia (Williams 2006, 147).

Williams przekłada wyjaśnienie preferencji gatunkowej na kwestię ulepszających zmian, formułując następujący fikcyjny przykład. Załóżmy, że na Ziemię przylatują przedstawiciele pozaziemskiej zaawansowanej cywilizacji. Przybysze są życzliwi i rozsądni oraz mają duże doświadczenie w tworzeniu pokojowych społeczeństw. Ponieważ z ich doświadczeń wynika, iż preferencja gatunkowa oraz autonomia w tworzeniu kultury wpływa destabilizująco i destruktywnie na społeczność, proponują bezbolesne usunięcie tych czynników. Williams zauważa, że ludzie, którzy byliby zwolennikami takiej zmiany musieliby albo używać argumentów formułowanych z „ludzkiego punktu widzenia”, które przeciwnicy zmian byliby w stanie zrozumieć, albo argumentów wspólnych zarówno dla ludzi, jak i dla obcych. Pierwsza opcja stawiałaby zwolenników zmian w paradoksalnej sytuacji, związanej ze znalezieniem w ludzkim punkcie widzenia elementów za jego odrzuceniem ${ }^{4}$. W drugim przypadku, nawet zakładając, że istnieją moralne zasady powszechne dla wszystkich racjonalnych istot, można wątpić, czy wspierałyby one podjęcie zmian (przeciwne stanowisko prezentuje: Savulescu 2009). Według Williamsa jest tak dlatego, że zasady te nie mówią, jak ułożyć sobie życie po zmianie (Williams 2006, 151; szczegółowe przykłady tego typu trudności prezentuje Agar, 2015).

Spór między biokonserwatystami i transhumanistami można w tym aspekcie zinterpretować jako spór o kategorię "rzeczywistych interesów” ludzkich istot. Pierwsi, odnosząc niekiedy to pojęcie do pojęcia natury, uznają, iż jest ona stałą podstawą typowych ludzkich cech i zachowań. Na tej podstawie uzasadniają oni dopuszczalność ingerencji terapeutycznych, mających na celu przywrócenie spowodowanych chorobą lub innym patologicznym stanem cech, które umożliwiają funkcjonowanie $\mathrm{w}$ ramach owej natury. Drudzy natomiast odnoszą pojęcie „rzeczywistych interesów” do zasady maksymalizacji, twierdząc, iż jeśli dana cecha znajdująca się na pewnym poziomie jest wartościowa (np. umożliwia zdobycie danej ilości dóbr), to obiektywnie pożądane są wszelkie ingerencje, które podnoszą daną cechę na wyższy poziom. W obu opisanych powyżej modelach możliwe jest wskazanie przypadków, które mogą być interpretowane w kategorii efektu status quo. 0 błąd taki można podejrzewać pacjenta, który nie zamierza

${ }^{4}$ Według Nicholasa Agara brak możliwości rozwiązania tego paradoksu przemawia za przyjęciem relatywizmu gatunkowego (Agar 2011, 12-15). 
korzystać z medycznych możliwości przywrócenia mu zdrowia. Nawet w tym przypadku jednak test odwrócenia nie musi prowadzić do prawdziwych wniosków. Chęć pozostania w dotychczasowym stanie może być uzasadniona zbyt wysokimi kosztami przystosowania się do nowych możliwości lub brakiem związku między tymi możliwościami a sensem życia danej jednostki. Konieczne jest zatem sformułowanie formalnych warunków pozwalających odróżnić sytuacje, w których podmiot posiada racje, by nie wybierać zmiany od tych, gdy jego decyzja jest motywowana na przykład lękiem przed obiektywnie pożądaną zmianą.

Według Williamsa kwestia niewłaściwego rozeznania rzeczywistych interesów nie leży tylko w tym, że podmiot nie ma wystarczającej wiedzy, która mogłaby mu w tym pomóc w podjęciu decyzji.

Jeśli podmiot nie jest świadomy, że pewna zmiana mogłaby być $\mathrm{w}$ jego interesie i jeśli $w$ rezultacie tej zmiany dochodzi on do wniosku, że leżała ona $\mathrm{w}$ jego interesie, to będzie to stanowiło dowód tylko wówczas, gdy przemiana jego perspektywy może zostać wyjaśniona przez odniesienie do ogólnej niezdolności, której podlegał $\mathrm{w}$ pierwotnym stanie i która została wyeliminowana lub złagodzona przez ową zmianę (Williams 1993, 42-43).

Zdefiniowanie owej „ogólnej niezdolności” musi, zgodnie ze stanowiskiem Williamsa, spełniać dwa warunki. Po pierwsze, niezdolność ta nie może być definiowana tylko i wyłącznie na podstawie przesłanek uzasadniających zmianę. Jeśli jakaś sekta religijna uzasadniałaby konieczność poddania się praniu mózgu tym, że po jego zakończeniu każdy będzie w stanie szczerze uznać swoją uprzednią niezdolność do zaakceptowania proponowanych twierdzeń religijnych, to tego rodzaju uzasadnienie nie spełniałoby pierwszego warunku. Po drugie, wspomniana definicja musi być połączona z normatywną koncepcją ludzkiego funkcjonowania w określonych okolicznościach kulturowych. Każda koncepcja ulepszania ludzkiej kondycji musi zawierać zatem również koncepcję zmian kulturowego otoczenia ulepszonych ludzi, włączając $w$ to refleksję nad nowymi sposobami komunikacji czy relacji międzyludzkich.

Argumentacja Williamsa pozwala na stwierdzenie, że $\mathrm{z}$ punktu widzenia podmiotów, które miałyby podlegać modyfikacjom, radykalne ulepszanie związane z możliwością utraty przez nie ich perspektywy byłoby nieuzasadnione, natomiast $\mathrm{w}$ przypadku pozostałych ulepszających ingerencji ciężar dowodu związany możliwością pogodzenia bezstronnej kalkulacji korzyści z indywidualnymi projektami tych podmiotów, leżałby po stronie zwolenników zmian. 


\section{Zakończenie}

Przedstawiona w tym artykule argumentacja nie pozwala na odrzucenie wszystkich możliwych ulepszających ingerencji. Kategoria "ogólnej niezdolności” może jednak służyć do dookreślenia różnicy między działaniami terapeutycznymi a doskonalącymi, zwłaszcza w kontekście projektu ulepszania moralnego. $\mathrm{Z}$ bezstronnego punktu widzenia utrata ludzkiej perspektywy jest jedynie kosztem, który należy wziąć pod uwagę w bilansowaniu ryzyka i korzyści. Z punktu widzenia podmiotu utrata "własnego" lub "naszego" punktu widzenia jest porównywalna z egzystencjalną katastrofą. W tym kontekście argumentacja biokonserwatywna Habermasa, Sandela czy McKibbena może być interpretowana nie jako przykład błędu status quo, lecz jako postulat poważnego uwzględnienia perspektywy podmiotów, jakimi jesteśmy, w dyskusji dotyczącej tego, jakie ingerencje biomedyczne dopuścić do szerokiego stosowania.

\section{Bibliografia}

Agar, N. 2010. Humanity's End: Why We Should Reject Radical Enhancement. MIT Press, Cambridge.

Agar, N. 2014. Truly Human Enhancement: A Philosophical Defense of Limits. MIT Press, Cambridge.

Bostrom N. \& Ord T. 2006. "The Reversal Test: Eliminating Status Quo Bias in Applied Ethics." Ethics 116: 656-679.

Buchanan, A. E. 2008. "Enhancement and the Ethics of Development." Kennedy Institute of Ethics Journal 18: 1-34.

-_- 2011a. Better Than Human: The Promise and Perils of Enhancing Ourselves. New York: Oxford University Press.

- - . 2011b. Beyond Humanity? The Ethics of Biomedical Enhancement. Oxford: Oxford University Press.

DeGrazia, D. 2007. "Human-Animal Chimeras: Human Dignity, Moral Status, and Species Prejudice." Metaphilosophy 38: 309-329.

Douglas, T. 2015. "The Harms of Enhancement and the Concluive Reasons View." Cambridge Quarterly of Healthcare Ethics 24: 23-36.

Fukuyama, F. 2002. Our Posthuman Future: Consequences of the Biotechnology Revolution. New York: Profile Books.

Habermas, J. 2003. Przyszłość natury ludzkiej. Czy zmierzamy do eugeniki liberalnej? Tłum. M. Łukasiewicz. Warszawa: Wydawnictwo Naukowe SCHOLAR.

Hainz, T. 2012. „Value Lexicality and Human Enhancement.” Technoethics 3: 54-65. 
Harris, J. 2010. „Moral Enhancement and Freedom.” Bioethics 25: 102-111.

Häyry, M. 2010. Rationality and the Genetic Challenge: Making People Better? Cambridge University Press: Cambridge.

Jonas, H. 1996. Zasada odpowiedzialności. Tłum. M. Klimowicz. Platan: Kraków. Kahneman, D. 2011. Thinking Fast and Slow. New York: MacMillan.

Kahneman, D. \& Tversky, A. 1979. "Prospect Theory: An Analysis of Decisions under Risk." Econometrica 47: 263-291.

Kass, L. 2002. Life, Liberty, and the Defense of Dignity. San Francisco: Encounter Books.

Manson, N. A. 2002. "Formulating the Precautionary Principle." Environmental Ethics 24: 263-74.

McKibben, B. 2004. Enough: Staying Human in an Engineered Age. New York: St. Matin's Press.

Patrone, T. 2013. "In Defence of Human Prejudice." International Journal of Technoethics 4: 26-38.

(NN) 2003. Beyond Therapy: Biotechnology and the Pursuit of Happiness. Washington, DC: President's Council on Bioethics.

Sandel, M. 2007. The Case Against Perfection: Ethics in the Age of Genetic Engineering. Cambridge, MA: Harvard University Press.

Savulescu, J. 2009. "The Human Prejudice and the Moral Status of Enhanced Beings: What Do We Owe the Gods?" In J. Savulescu \& N. Bostrom (eds.), Human Enhancement. Oxford: Oxford University Press: 211-247.

Savulescu, J. \& Persson, I. 2012. Unfit for the Future: The Need of Moral Enhancement. Oxford: Oxford University Press.

Singer, P. 1995. Animal Liberation. London: Pimlico.

Singer, P. 2009. "Speciesism and Moral Status." Metaphilosophy, 40: 567-581.

Sunstein, C. 2005. Laws of Fear: Beyond Precautionary Principle. Cambridge: Cambridge University Press.

Williams, B. 1993. Ethics and the Limits of Philosophy. London: Fontana.

Williams, B. 2006. "The Human Prejudice". In idem, Philosophy as a Humanistic Discipline. Princeton: Princeton University Press:135-152.

Żuradzki, T. 2014. „Nowa liberalna eugenika: krytyczny przegląd argumentów przeciwko biomedycznemu poprawianiu ludzkiej kondycji fizycznej lub umysłowej". Diametros 42: 204-226. 


\title{
Wojciech Lewandowski (Lublin)
}

\section{Biokonserwatyzm i preferencja status quo}

\begin{abstract}
Abstrakt. Stanowisko biokonserwatywne głosi, że należy powstrzymać upowszechnianie się ingerencji biomedycznych pozwalających na ulepszanie ludzkiej kondycji. Jeden $\mathrm{z}$ argumentów przeciwko temu stanowisku polega na wykazaniu, iż jest ono oparte na błędzie status quo polegającym na nieuzasadnionej preferencji aktualnego stanu rzeczy. Zgodnie $\mathrm{z}$ tym argumentem racje przeciwko ulepszającym ingerencjom nie są konkluzywne. Celem artykułu jest wskazanie możliwości takiej interpretacji stanowiska biokonserwatywnego, przy której unika ono zarzutu błędu status quo.
\end{abstract}

Słowa kluczowe: biokonserwatyzm, status quo, racje konkluzywne, ulepszanie ludzkiej kondycji, ingerencje biomedyczne, perspektywa podmiotu, bezstronność.

\begin{abstract}
Bioconservative view holds that we should prevent dissemination of biomedical inteventions enhancing human capacities. One of arguments against this view shows that it is based on status quo bias which gives unjustified preference for actual state of affairs. According to this argument reasons against human enhancement are not conclusive. The aim of this article is to show the possibility of the interpretation of the bioconservative view, under which it is possible avoiding the status quo bias objection.
\end{abstract}

Keywords: Bioconservatism, status quo, conclusive reasons, human enhancement, biomedical interventions, agent's perspective, impartiality.

Ethics in Progress (ISSN 2084-9257). Vol. 6 (2015). No. 1, pp. 72-84.

doi: 10.14746/eip.2015.1.7 